\title{
Reviewing the effectiveness of the Oxford tutorial system in teaching an undergraduate qualifying law degree: a discussion of preliminary findings from a pilot study
}

\section{Introduction}

\subsection{The Oxford tutorial system}

At undergraduate level the tutorial system at the University of Oxford has several distinctive features, which serve to make it almost unique in UK Higher Education. The common elements of tutorial teaching are summarised by the Oxford Learning Institute (OLI) as follows: students meet individually or in very small groups with a tutor from their discipline in their college, typically once a week or once a fortnight; students spend time independently reading and preparing written work for the tutorial; and students discuss their written work with the tutor, giving them an opportunity to receive constant feedback from their tutors. ${ }^{1}$ This does not replace but is in addition to lectures and larger classes such as seminars that students at Oxford attend, in common with their peers at other universities. ${ }^{2}$

The central issue to be explored in this paper is the effectiveness of this system of teaching. In doing so this paper will aim to identify some of the gaps in the existing research into the Oxford tutorial system and propose avenues for further study. To focus and limit the scope of this paper, it is the Oxford tutorial system that will be examined, although it is acknowledged that this system has several features in common with similar types of teaching at other Higher Education institutions, in particular the Universities of Cambridge and Buckingham in the UK, as well as with institutions outside the UK, such as certain liberal arts colleges in the USA. The scope of this paper is also limited to consideration of tutorial teaching in the context of an undergraduate qualifying law degree (QLD), specifically the Bachelor of Laws (LL.B) degree, which is the academic stage of training for students intending to practice as solicitors or barristers in England and Wales. As well as being the area most familiar to the writer, it will be demonstrated that there are several disciplinespecific issues and concerns which make consideration of the tutorial system for undergraduates intending to practice as legal professionals particularly relevant and enlightening.

\subsection{Wider relevance}

It is considered that a study on this subject is timely in light of recent findings by the Oxford University Student Union (OUSU) ${ }^{3}$ and updated policy guidance issued by the Oxford University Education Committee (OUEC), ${ }^{4}$ which will be discussed later in this paper. A critical review of the effectiveness of the Oxford tutorial system in the teaching of an undergraduate QLD is also particularly important in light of recent recommendations in relation to assessment and feedback for law students made by the regulatory bodies for the legal profession, also discussed below. Ascertaining the effectiveness of the tutorial system is therefore important in part to address recent concerns set out in studies and reports such as those by OUSU and

\footnotetext{
${ }^{1}$ Oxford Learning Institute (OLI) Tutorial Teaching (2016)

https://www.learning.ox.ac.uk/support/teaching/resources/teaching/ [Retrieved 17 January 2016]

2 W.G. Moore, The Tutorial System and its Future. (Oxford: Pergamon Press, 1968).

${ }^{3}$ Oxford University Student Union (OUSU) Undergraduate Teaching Review Report (University of

Oxford, 2010).

${ }^{4}$ Oxford University Education Committee (OUEC) Policy Guidance on Undergraduate Learning and

Teaching, (University of Oxford, 2008).
} 
OUEC about funding of tutorials, teaching quality, inconsistency, lack of preparation for assessment etc, which reflect wider concerns in Higher Education beyond Oxford.

The starting point for this paper will be to critique current positions in literature, policy and practice and to offer new insights into significant issues. The literature review in section 2 identifies some of the gaps in the existing research into the Oxford tutorial system. There is, for example, little data available on how existing students actually experience tutorials. Those who support the Oxford tutorial system rarely seem to be able to put forward any empirical evidence to support what are usually theoretical arguments in favour of it. In particular, it does not appear that any research has been done into the experience of law students of the Oxford tutorial system. This paper will therefore focus on the student experience of tutorials by reporting on tutorial observations and interviews with the students involved. In theory, this is a system, with its emphasis on argument, debate, independent thinking, critical reasoning, and the ability to apply and develop one's own understanding, which is particularly beneficial to aspiring lawyers. Finding out whether students who have gone on to careers in law have in reality found the apparent benefits of the Oxford tutorial system to be helpful preparation therefore appears to be a worthwhile exercise. Bringing together and building on previous research findings will therefore be necessary, but it will also be important to test these findings and develop new approaches to research in the largely unexplored context of teaching and learning for an undergraduate QLD.

The rest of this paper is divided into sections. Section 2 is a literature review, which considers what the Oxford tutorial is and looks at academic critique of the system in broad terms, before formulating research questions for a pilot study that focuses on critical thinking and a critical dialogue around feedback. Section 3 sets out the methodological basis for the study. Section 4 is a discussion of the findings of tutorial observations and student interviews by reference to key themes such as the strengths and weaknesses of tutorials and their role in assessment and feedback, critical thinking and critical dialogue. Section 5 is a conclusion that will seek to provide a definitive response to the issue of the effectiveness of the Oxford tutorial system in the teaching of an undergraduate QLD by reference to the research questions set out in section 2 .

\section{Literature Review}

\subsection{Background to legal and tutorial teaching at Oxford}

The academic year at Oxford runs from October to June and is year is divided into three terms: Michaelmas (autumn), Hilary (spring), and Trinity (summer), which each last for eight weeks. ${ }^{5}$ The Oxford Law Faculty website confirms that "The BA in Jurisprudence is our regular three year undergraduate law degree, equivalent to what in some universities would be called an LLB. It is also a 'qualifying law degree' for the purpose of practice as a solicitor or barrister in England and Wales." ${ }^{6}$ The programme is non-modular and students are required to take unseen written examinations at the end of their third and final year on all of the subjects they have studied since the third term of their first year. ${ }^{7}$ These include Contract Law, Tort Law, Administrative Law, Land Law, Trusts Law, Jurisprudence, European Union Law and two options (Jurisprudence alone is examined by an essay as well as an unseen

\footnotetext{
5 University of Oxford website,

https://www.ox.ac.uk/staff/about the university/new to the university/university year?wssl=1 [Retrieved 17 April 2017].

${ }^{6}$ Oxford Law Faculty website, https://www.law.ox.ac.uk/admissions/undergraduate/ba-jurisprudence [Retrieved 17 April 2017].

${ }^{7}$ ibid.
} 
written examination). ${ }^{8}$ Students must attend seven or eight tutorials in each subject, either weekly (over one term) or fortnightly (over two terms) and can also attend noncompulsory lectures and preparatory classes based on the recommendations of their tutors. ${ }^{9}$ Students are expected to write an essay for each tutorial and on average have three tutorials every two weeks. ${ }^{10}$ Professional legal skills are also taught separately via the non-credit bearing Legal Research and Mooting Skills Programme, successful completion of which is nonetheless essential for all law students at Oxford and involves taking part in a moot following a lecture and a seminar. ${ }^{11}$

Professor Benjamin Jowett, former Master of Balliol College, is traditionally credited with having been the guiding influence behind the establishment of the tutorial system at Oxford based on the Socratic method. ${ }^{12}$ Fox describes the Socratic method in these terms: "By questioning, a pupil is led to an impasse from which he realizes the error of his starting point." 13 The method thus involves the stimulation of critical thinking by argumentative dialogue. As stated by Beck: "Socratic dialogues are the most well known examples of argumentation through questioning in critical discussions." 14 In the 1960s, the rapid growth of new universities throughout Britain resulted in accusations that the tutorial method was outmoded, elitist and inefficient, large lectures being deemed to be the more appropriate method of teaching in the modern university. A defence of the tutorial method quickly followed in the wake of these changes. Moore argued that the tutorial method's individual focus and unique ability to foster dialogue, argumentation, and independent thought outweighed any criticism against it. Today the OUEC is unequivocal about its commitment to the centrality of the tutorial method: "The tutorial system has given Oxford its worldwide reputation for teaching at undergraduate level and is strongly valued by students and teachers alike." 15

The Oxford tutorial system has been evaluated by several academics, who have expressed contrasting views on its effectiveness. Palfreyman argues that student tutorials are generally more academically challenging and rigorous than standard lecture and test format courses, because during each session students are expected to orally communicate, defend, analyse, and criticise the ideas of others as well as their own in conversations with the tutor and fellow-students. ${ }^{16}$ As a pedagogic model, Palfreyman argues, the tutorial system has great value because it creates learning and assessment opportunities that are highly authentic and difficult to fake. Like other proponents of the Oxford tutorial system, Palfreyman seems to see it as innately being more demanding than other methods of teaching, mainly because it is a system which requires students to engage in academic discussion with their tutors and peers. The suggestion seems to be that students are thereby encouraged to learn their subject of study more thoroughly to avoid having their lack of understanding exposed in the tutorial setting. Palfreyman's views are contestable, however, as he appears to assume that academic discussions do not also take place in lectures and seminars and that students may therefore be equally careful in their preparation for those methods of teaching. Determining the criteria by which the effectiveness of the Oxford tutorial system in teaching an undergraduate qualifying

\footnotetext{
8 ibid.

${ }^{9}$ ibid.

10 ibid.

11 ibid.

12 Moore, supra n.2, p.11.

13 R. Fox, 'Tutorials in Greats and History: The Socratic Method'. In Palfreyman, D., ed. The Oxford Tutorial: "Thanks, You Taught Me How to Think," 2nd ed. (Oxford: Blackwell's, 2008) p.56.

${ }^{14}$ R. Beck, The Pedagogy of the Oxford Tutorial, conference paper presented at the Tutorial Education: History, Pedagogy, and Evolution conference, Lawrence University, Appleton, WI, March 31 - April 1, 2007 http://www.leejones.tk/teaching/beck.doc [Retrieved 1 July 2016] p.7.

15 OUEC, supra n.4, p.8.

${ }^{16}$ D. Palfreyman (Ed.), The Oxford Tutorial: "Thanks, You Taught Me How to Think, "2nd ed. (Oxford: Blackwell's, 2008).
} 
law degree may be judged is therefore crucial, and this will be addressed in the following sections.

\subsection{Critical thinking}

The importance of students developing critical thinking skills through tutorial teaching appears central to the system. The OLI refers to the expectation that students will do more than just absorb and selectively reproduce information: "...we require them critically to reconstitute discipline-based knowledges and actively to develop discipline-based aptitudes." ${ }^{17}$ The OLI goes on to state that the tutor's role is to encourage students to engage with the knowledge they have encountered, constructing and re-constructing their own understanding: "By demonstrating the methods of the scholar, the best tutors enable their students to achieve their own scholarly independence." ${ }^{18}$ The tutorial system appears to encourage critical thinking, as it is a teaching model that is based on demonstrating to students by example the scholar's approach to learning in each discipline and encouraging students to think for themselves. This approach closely aligns with the most commonly accepted aspects of critical thinking as summarised by Golding: knowing how to evaluate or analyse, having the disposition and tendency to be reasonable or analytical, constructing and evaluating reasoned judgements, and understanding the subject matter you are thinking about. ${ }^{19}$

Of course, law students do pursue other careers (only around $25 \%$ of law graduates become solicitors for example) ${ }^{20}$ and this is acknowledged by the following statement in the Oxford Law Moderations Handbook: "We make no assumption that students taking our BA degrees should go on to become practising lawyers." ${ }^{21}$ The Handbook also, however, goes on to state: "But we recognise that most students wish to ensure that their law degree gains them exemption from the first stage of legal professional training in England and Wales, at any rate so as to keep that option open. Our BA degrees are accordingly constructed in such a way as to allow this." 22 Assessing the extent to which the Oxford tutorial system encourages critical thinking therefore seems relevant in the context of a subject like law. Collins, for example, has identified the need for law students to be assessed on critical thinking, oral communication and the art of argument, all of which are vital to the practice of law. ${ }^{23}$ Critical thinking is something that Golding feels students learn to do precisely because of their participation in what he calls a "community of inquiry" 24 set up by their teachers. The community of inquiry concept as referred to by Golding seems to echo that of the Oxford tutorial system: it is a group which "...actively engage(s) in dialogue over topics of interest, in the service of constructing knowledge and common understanding, and internalising the discourse of the inquiring community." 25

\subsection{Professional legal skills}

\footnotetext{
17 OLI, supra n.1, p.3.

$18 \mathrm{OLI}$, supra n.1, p2.

${ }^{19} \mathrm{C}$. Golding, 'Educating for critical thinking: thought-encouraging questions in a community of inquiry', (2011) 30(3) Higher Education Research and Development p.358.

20 The Law Society, Entry Trends (2015) https://www.lawsociety.org.uk/Law-careers/Becoming-asolicitor/Entry-trends/ [Retrieved 17 April 2017].

21 Oxford Law Moderations Handbook, https://www.law.ox.ac.uk/sites/files/oxlaw/mods handbook finalversion1 16-17.pdf [Retrieved 17 April 2017].

22 ibid.

${ }^{23} \mathrm{P}$. Collins, 'Inclusive team assessment of off-campus and on-campus first year law students using instantaneous communication technology' (2010) 44(3) The law Teacher p.314.

${ }^{24}$ Golding, supra n.19, p.359.

25 ibid.
} 
Shale attempts to engage with the issue of the effectiveness of the Oxford tutorial system in an essay which considers the question of what higher learning is, how it happens and what the system contributes to the learning of students engaged in it. ${ }^{26}$ Having defined 'higher learning' as a process of questioning and applying knowledge (rather than merely memorizing it), Shale makes a case for the advantages of the Oxford tutorial system but admits that there is insufficient data available on how students experience tutorials, which highlights an important area for further study on this subject. One of the few pieces of research done on Oxford University students' conceptions of the role of the tutorial in their learning by Ashwin revealed differing conceptions, ranging from the tutorial involving the tutor explaining to the student what the student did not know, to the tutorial involving the tutor and the student in exchanging different points of view and both coming to a new understanding of the topic under discussion. ${ }^{27}$ These differing conceptions of the tutorial system by students are perhaps unsurprising considering a later study by Ashwin, which also identified variations in academics' accounts of tutorials, these differences often being subject-based. ${ }^{28}$

Shale's arguments are particularly important in the context of an undergraduate QLD, which aims to prepare students for a career as a legal professional. It might seem that encouraging a questioning mind and a desire for deeper understanding is not necessary for law students, who ultimately need only to pass the LL.B with sufficient grades to qualify for the vocational stage of their training (and to meet the minimum academic criteria to be hired as solicitors or barristers by firms and chambers). But simply memorizing enough information to be able to pass assessments with the right grades will not be enough for a successful career in legal professional practice, where they will be called upon to apply their theoretical knowledge to real-world situations, understand developing legal principles in line with new legislation and case law, and test (and in some situations develop) accepted legal thinking. This requires the sort of independent thinking and critical, reasoning mind that the Oxford tutorial system is commonly argued to encourage.

A number of recent government studies focus on professional skills and their place in legal education in order to maintain competitiveness on the global stage. These include the DfEE's 1998 consultation paper, 'The Learning Age', which was subsequently integrated into the Subject Benchmarks for teaching assessment by the Quality Assurance Agency for Higher Education, 2000-2002;29 the First Report on Legal Education and Training by the Lord Chancellor's Advisory Committee on Legal Education and Conduct in 1996; ${ }^{30}$ and the Leitch Review of Skills in 2006. ${ }^{31}$ The importance of considering the specific needs of students from culturally diverse backgrounds in relation to curriculum design, assessment and feedback has also been made clear by the regulatory bodies for both UK higher education and the legal profession in England and Wales. The Higher Education Academy has identified law specifically as an area where students, who may previously not have had such prior opportunities, should have the chance to develop the skills required for a legal

\footnotetext{
${ }^{26} \mathrm{~S}$. Shale, 'The Oxford Tutorial in the Context of Theory on Student Learning: "Knowledge is a wild thing, and must be hunted before it can be tamed"'. In Palfreyman, D., ed. The Oxford Tutorial: "Thanks, You Taught Me How to Think," 2nd ed. (Oxford: Blackwell's, 2008) pp.85-90.

${ }^{27}$ P. Ashwin, 'Variation in students' experiences of the Oxford tutorial' (2005) 50 Higher Education pp.631-644.

${ }^{28}$ P. Ashwin, 'Variation in academics' accounts of tutorials' (2006) 31 (6) Studies in Higher Education pp.651-665.

29 Department for Education and Employment, The Learning Age: a renaissance for a new Britain (London: DfEE, 1998).

${ }^{30}$ ACLEC, supra n.22.

${ }^{31}$ Department for Education and Employment, Prosperity for all in the Global Economy: World Class Skills (Leitch Review of Skills) (London: DfEE, 2006).
} 
context through inclusive approaches to learning and teaching. ${ }^{32}$ Specific recommendations in relation to curriculum design, assessment and feedback for law students have been made by the LETR, the report that followed a review of the academic stage of legal education and training conducted on behalf of the regulatory bodies for the legal profession. ${ }^{33}$ The main thrust of these various reports and studies is the role of skills teaching in enhancing the "transformative potential" 34 rather than the specific knowledge of Law graduates.

Embedding lifelong learning skills and employability training is therefore a priority for university law schools and the Oxford tutorial system appears to potentially be an effective way of doing this. In this context, the views of Mirfield on the Oxford tutorial system are instructive. In his opinion, given the unique vulnerability of law to "the latest groundbreaking new material, say a case from our highest court," the students who are going to get the best law degrees are those "who are still thinking," something that he feels they are well prepared for by the Oxford tutorial system, with its emphasis on argument and independent thought. 35 With its smaller class sizes and relatively greater contact time with tutors, Mirfield also cites another benefit of the Oxford tutorial system as being that "Failures and weaknesses are noticed early and can be addressed." 36 Mirfield does not put forward any empirical evidence to support his views, therefore this paper will seek to explore whether the Oxford tutorial system does demonstrably encourage students' ability to argue and think independently or whether these are simply attributes that come more naturally to more able students, regardless of the method of teaching. Whilst the potential identified by Mirfield for the Oxford tutorial system to ensure that "individuals do not fall down cracks" 37 is recognised, another issue to be explored is whether student weaknesses are not only being noticed by tutors but being dealt with (and if not, whether this is due to any systemic failings).

\subsection{Assessment and feedback}

The Oxford tutorial system also has potential benefits in terms of assessment and feedback as well as teaching by developing students' ability to regulate their own learning. The OUEC makes clear the importance of feedback to the tutorial system: "Tutorial teaching provides regular and substantial feedback and formative assessment." ${ }^{38}$ Effective feedback should "...enable learners to work towards selfregulatory learning so that they can plan and manage the improvement of their own learning in the future." ${ }^{39}$ Cassidy ${ }^{40}$ emphasises the need for students to develop selfregulated learning skills, not only to achieve academically while they are in Higher Education but also for maintaining the capacity for employment and lifelong learning (something that is particularly important to aspiring lawyers, who are obliged by their professional bodies to engage in continuous professional development throughout

\footnotetext{
32 Higher Education Academy, Inclusive curriculum design in higher education - considerations for effective practice across and within subject areas (Law) (HEA, 2011)

https://www.heacademy.ac.uk/sites/default/files/resources/Law.pdf [Retrieved 7 January 2016].

${ }^{33}$ Legal Education and Training Review (LETR), Setting Standards: The future of legal services education and training regulation in England and Wales (2013).

${ }^{34}$ L. Harvey and S. Mason, 'A quality graduate', in Tait, J. and Knight, P., eds. The Management of Independent Learning (London: SEDA, 1996) p.15.

${ }^{35}$ P. Mirfield, 'Teaching law, Learning law: Growing Up Intellectually'. In Palfreyman, D., ed. The Oxford Tutorial: "Thanks, You Taught Me How to Think," 2nd ed. (Oxford: Blackwell's, 2008) p.46.

${ }^{36}$ Mirfield, supra n.35, p.46.

37 ibid.

38 OUEC, supra n.4, p.9.

39 D. Boud and E. Molloy, Feedback in Higher and Professional Education: understanding it and doing it well (Oxon: Routledge, 2013) p.2.

${ }^{40} \mathrm{~S}$. Cassidy, 'Self-regulated learning in higher education: identifying key components and processes' (2011) 36(8) Studies in Higher Education pp.989-1000.
} 
their careers). This concept of self-regulated learning refers to the way in which students can regulate aspects of their thinking, motivation and behaviour during learning e.g. by setting learning goals and strategies for achieving them. ${ }^{41}$ There seems to be a consensus in the relevant literature that effective feedback should mainly enable learners to work towards self-regulated learning: Beaumont et al. suggest that courses should use structured feedback practices to explicitly develop self-regulated learning ${ }^{42}$ and Sadler agrees that the "mere provision of feedback does not necessarily lead to improvement..." and that "...feedback should therefore empower students to become self-regulated learners." 43 There are, however, practical challenges in developing self-regulated learners - motivating passive students being one of the main issues pointed out by Zimmerman. ${ }^{44}$ However, also as mentioned by Zimmerman, heightened motivation and proactively seeking out opportunities to learn are important aspects of self-regulated learning.

In this regard a point made by Carless concerning the importance of students developing the kind of self-monitoring skills required for lifelong learning therefore seems to be particularly pertinent in relation to law students. ${ }^{45}$ Almost any profession that a student enters after graduation will require them to learn new knowledge and skills and this is particularly so for law, where legal knowledge may change in light of the latest new statute or court judgement and where there is a requirement by their professional bodies that qualified lawyers do continuing professional development courses throughout their working lives. Another point made by Higgins et al., ${ }^{46}$ Rust et al ${ }^{47}$ and Weaver ${ }^{48}$ is that to be effective, feedback on its own is not enough - what must be communicated to students is tacit knowledge, new social practices and forms of expression, the meanings and demands of assessments etc., so that students can understand feedback and put it into practice. Tacit knowledge (as defined by Rust et al. ${ }^{49}$ and Sadler ${ }^{50}$ ) is something known that is difficult to express, highly personal, hard to formalise, experience based and the very essence of a great deal of professional expertise (this last point is particularly relevant to a vocational course such as a QLD, which is often taught by legal practitioners). Tacit knowledge can therefore only be revealed to students if they share experiences involving observation, imitation, dialogue and practice..$^{51}$ Tutorials appear to meet the specific needs of law students by offering them the chance to engage in the sort of discussion and critical argument that will prepare them for legal professional practice, as well as passing on the tacit knowledge in this particular area of professional expertise and developing students' ability to regulate their own learning.

These issues seem to tie in with the more general challenges of providing effective feedback which have been identified in the relevant literature, and which

\footnotetext{
${ }^{41}$ D. Nicol and D. Macfarlane-Dick, 'Formative Assessment and Self-regulated Learning: a model and seven principles of good feedback practice' (2006) 31(2) Studies in Higher Education p.199.

${ }^{42}$ C. Beaumont, M. O'Doherty and L. Shannon, 'Reconceptualising Assessment Feedback: a key to improving student learning?' (2011) 36(6) Studies in Higher Education p.683.

${ }^{43}$ D. Sadler, 'Beyond feedback: developing student capability in complex appraisal' (2010) 35(5) Assessment \& Evaluation in Higher Education p.536.

${ }^{44}$ B. Zimmerman, 'Self-Regulated Learning and Academic Achievement: An Overview' (1990) 25(1) Educational Psychologist pp.3-17.

45 D. Carless, 'Differing perceptions in the feedback process' (2006) 31(2) Studies in Higher Education p.230.

${ }^{46}$ R. Higgins, P. Hartley, and A. Skelton, 'Getting the Message Across; the problem of communicating feedback' (2001) 6(2) Teaching in Higher Education pp.269-274.

${ }^{47} \mathrm{C}$. Rust, M. Price and B. O'Donovan, 'Improving students' learning by developing their understanding of assessment criteria and processes' (2003) 28 (2) Assessment \& Evaluation in Higher Education pp.147-164.

${ }^{48}$ M. R. Weaver, 'Do students value feedback? Student perceptions of tutors' written responses' (2006) 31(3) Assessment \& Evaluation in Higher Education pp.379-394.

49 Rust et al., supra n.47, p.152.

50 Sadler, supra n.43, p.546.

${ }^{51}$ Rust et al., supra n.47, p.152.
} 
have prompted proposals to address these issues. Carless notes that students are often dissatisfied with the feedback they receive due to what they perceive as the lack of specific recommendations for improvement, the difficulty in interpretation of feedback and the negative impact that it may have on their confidence and selfperception. ${ }^{52}$ For Carless, the issue seems to boil down to the differing perceptions of the role and importance of the feedback process between students and tutors in a number of areas e.g. tutors believe that they are providing more detailed feedback than students do, tutors perceive their feedback to be more useful than students do and so on. These contrasting viewpoints represent a barrier to be overcome in order for feedback to be more effective. The suggestion put forward by Carless is that 'assessment dialogues' (i.e. discussions taking place between students and tutors in order to demystify the assessment process) are one way to overcome this barrier. Weaver (2006) highlights different problems with feedback from the student perspective (e.g. comments that are too general or vague, lack of specific guidance on how to improve, too much focus on the negative and lack of relation to assessment criteria) but seems to draw a similar conclusion to Carless that the difference between the perceptions of students and their tutors is an important issue ${ }^{53}$, as do Beaumont et al. ${ }^{54}$ In a proposal similar to that of Carless, Weaver suggests that tutors need to avoid the possibility of students misinterpreting their feedback by using clear and constructive feedback. ${ }^{55}$ In explaining what is meant by constructive feedback, Weaver explicitly refers to feedback that is set in the context of assessment criteria and learning outcomes, helps students know how to improve, helps to explain gaps in their knowledge and understanding, and contains both diagnosis and guidance.

Nicol has proposed a 'dialogical approach' to feedback to help students to develop the ability to regulate their own learning. ${ }^{56}$ Nicol's proposal, like those of Carless and Weaver as referred to above, essentially resembles the Oxford tutorial system in moving away from the somewhat impersonal model of one-way written communication that commonly represents feedback in UK mass Higher Education today, to discussions in smaller groups, not just been tutors and individual students but also between the students themselves. Smaller groups and greater contact time with tutors seems to ensure that failures and weaknesses are noticed early and can be addressed. In theory Nicol's is also a model, with its emphasis on argument, discussion and development of lifelong learning skills, that is particularly beneficial to aspiring lawyers, who will need such expertise in their future professional lives. Furthermore, as noted above, the nature of the dialogical approach to feedback in the Oxford tutorial is a critical dialogue, with the focus being on the student having to self-question and self-criticise in relation to their essays and tutor questions. This is therefore a model that, through small group discussion of feedback, offers students an opportunity to develop their critical thinking skills. The need to improve such skills is also identified by the $\operatorname{LETR}^{57}$ as a key area of concern in UK Higher Education.

\subsection{Criticism of the Oxford tutorial system}

The Oxford tutorial system also has several potential failings, however, as recognised by Mirfield. ${ }^{58}$ These include students who remain silent or who are otherwise unsuited to tutorials and who would benefit more from the other methods of

\footnotetext{
52 Carless, supra n.45, p.220.

53 Weaver, supra n.48, p.394.

54 Beaumont et al., supra n.42, p.687.

55 Weaver, supra n.48, p.394.

56 D. Nicol, 'From Monologue to Dialogue: improving written feedback processes in mass higher education' (2010) 35(5) Assessment and Evaluation in Higher Education pp.501-517.

${ }^{57}$ LETR, supra n.33, pp. xiv, 128, 132.

58 Mirfield, supra n.35, p.46.
} 
teaching at Oxford University e.g. lectures, where subjects are explained to students who have not yet achieved a sufficient level of understanding to be able to explain the subject for themselves, and seminars, where there are larger groups of students engaged in various classroom learning activities. This echoes the concerns of Brookfield that participation in group discussion can be a mixed blessing, as he points out: "The longer one stays silent, the harder it is to make that first contribution." 59 This hints at a wider issue that will be explored in this paper i.e. whether it is only 'brighter' students, such as those who have achieved the level of qualification sufficient to secure entrance to the University of Oxford, who can benefit from the tutorial system.

Another problem with the system is the risk identified by Mirfield that students end up relying only upon the essays that they produced for tutorials in their revision for exams. ${ }^{60}$ A study by OUSU identified that students valued the contribution of discussion to their learning, particularly where this took place in small groups and in tutorials with at least one other student. ${ }^{61}$ The students, however, felt that tutors must have good skills in facilitating discussions and must make the intended purpose of discussions clear to students. Some students had also stated "that the classes which they had attended had not been successful, largely because the purpose behind the classes had been unclear." ${ }^{2} 2$ Again, this hints at a wider question that this paper will seek to answer: even if the arguments commonly put forward in support of the tutorial system (e.g. independent thinking, skills of argument etc.) are accepted, does it necessarily follow that it is the best way to prepare students for taking assessments and, if not, does this invalidate the system altogether?

Another of the criticisms commonly levelled at the tutorial method referred to in section 2.1 of this paper is that it is costly and inefficient compared to teaching in larger groups. Dawkins, for example, suggests that the Oxford tutorial system is not economically viable and cannot therefore be replicated by other universities for resource reasons. Of the tutorial method Dawkins states: "The cost is so great that it cannot be met from income. The tutorial system is a luxury, subsidised by eating into endowment capital." 63 Dawkins also warns against the "obvious response to the economic imperative being to move towards tutoring... in groups so large as to belie the name tutorial" 64 - in the process losing the corresponding benefits to students of smaller class sizes and greater contact time with their tutors. Any conclusions reached as a result of this study regarding the effectiveness of the tutorial method must therefore take into account the fact that, in practice, economic factors may well limit the transferability of this model to universities that do not have the endowment capital of Oxford.

\subsection{Research question}

The preceding sections of this literature review explain what the Oxford tutorial system is, highlight some of its original aims and identify what it was intended to achieve, relating this to the teaching of an undergraduate QLD. The system's potential to stimulate critical thinking by argumentative dialogue and to foster a critical dialogue around feedback appear particularly relevant to law students considering the views of Mirfield, Palfreyman and others as discussed above. To

\footnotetext{
59 S. Brookfield, 'Through the Lens of Learning: how the visceral experience of learning reframes teaching', in: Paechter, C., Edwards, R. M., Harrison, R. and Twining, P. (Eds.) Learning, Space and Identity (London: Sage, 2000), p.70.

${ }^{60}$ Mirfield, supra n.35, p.46.

61 OUSU, supra n.3, p.3.

62 OUSU, supra n.3, p.15.

${ }^{63}$ R. Dawkins, 'Evolution in Biology Tutoring?'. In Palfreyman, D., ed. The Oxford Tutorial: "Thanks, You Taught Me How to Think, "2nd ed. (Oxford: Blackwell's, 2008) p.51.

64 ibid.
} 
investigate the effectiveness of the Oxford tutorial system in the teaching of an undergraduate QLD, this paper therefore focuses on the following research question: 'Does the Oxford tutorial system help to stimulate critical thinking and foster a critical dialogue around feedback among law students?' This question highlights the main purpose of the Oxford tutorial system as being to help students to learn to think for themselves by developing their ability to engage in higher-order thinking and selfregulated learning.

In relation to critical thinking, it is the extent to which tutorials stimulate students' ability to interpret, criticise or apply their knowledge rather than simply memorising and recalling information that needs to be examined. It will therefore be necessary to look at what strategies are being used in the tutorials to encourage critical thinking in students through the exercise of self-criticism, self-reflection and self-questioning and to ask whether their ability to think critically improved in terms of their capacity to self-reflect, self-criticise and self-question more effectively. In relation to a critical feedback dialogue, what needs to be examined is the extent to which tutorials offer students the opportunity to self-regulate their learning and socially construct their understanding of the subject through feedback from their tutor and peers. Issues to be explored in this context are the extent to which tutors go beyond simply providing feedback by empowering the students to regulate aspects of their thinking, motivation and behaviour during learning, for example by setting their own learning goals and strategies for achieving them. Linked into this will be the issue of exploring how well tutorials prepare students, through a critical dialogue around feedback, for assessment (mainly time-constrained exams) and legal practice (e.g. adapting to changes in legal knowledge).

The preceding sections also highlight both the importance of student perceptions of feedback and the fact that there is insufficient data available on how students experience tutorials. To answer this research question, therefore, gathering data from students is vital and the methodology involved in doing so is explained in the next section.

\section{Methodology}

Consideration of the effectiveness of the Oxford tutorial system involved answering the research question identified above. A case study design was used for this, the main stage of primary data collection in this pilot study i.e. some elements of the design, particularly data analysis, were not finalised until the data collection process was complete while other elements, such as the data collection methods, were pre-specified. ${ }^{65}$ The main aim of this study was evaluation, which can be approached using a fixed, flexible or multi-strategy design depending on the specific purpose of the evaluation. ${ }^{66}$ It was considered appropriate for this design to be used given that the focus of the evaluation in this study was on a mixture of both the processes and outcomes of a specific teaching strategy, a purpose for which a multistrategy design is most often used. ${ }^{67}$

The data collected were qualitative: the views of undergraduate law students, which as identified in the literature review, are an area where there is currently insufficient data available. While this pilot study was not therefore intended to be statistically significant, it was considered that qualitative discussions of the student learning experience are potentially highly valuable, as they provide a level of detail that a quantitative study does not permit. There were two aspects to this study: the first involved observation of tutorials for evidence of learning gain by students during the tutorial and the second involved qualitative analysis of responses to group

\footnotetext{
${ }^{65}$ N. Walliman, Social Research Methods (London: Sage, 2006) p.45.

${ }^{66}$ C. Robson, Real World Research. (London: Wiley, 2011) p.167.

67 ibid.
} 
interviews of the same students, with questions directed at the effectiveness of the tutorial system in teaching a QLD. The units of analysis were current Oxford University undergraduate law students. The data so collected were then analysed to answer the relevant research question for this study.

In terms of what was being achieved from the observations and interviews, it was considered that they would be useful to explore several issues pertinent to this study. The purpose of the observations was to reveal activities, types of interaction, and the tutor's role in stimulating critical thinking and a feedback dialogue and to look at the range of student responses that show learning gain, engagement or otherwise. The purpose of the interviews was to reveal student perceptions of the tutorials - did they enjoy them, were they engaged, was feedback useful, did they feel better prepared for assessment, has their ability to think critically improved, what worked and did not work for them, what would they change and so on. The students were also asked whether they felt better prepared for legal practice. Although this was potentially a difficult question for students without first-hand knowledge of legal practice to answer, given the importance of teaching professional legal skills by means of the tutorial method, as discussed in section 2.3 above, it was considered worthwhile to ask it. This question also yielded interesting responses from students, discussed in section 4.1 below.

For this pilot study, all the law tutors at the University of Oxford who were teaching in Trinity term 2016 (24 $4^{\text {th }}$ April to $18^{\text {th }}$ June 2016) were identified through the university website. These were tutors who were teaching First and Second Year law undergraduates, since no teaching of Third Years occurs during Trinity term at Oxford due to Final Honours examinations taking place in this period. The tutors were contacted by e-mail, given a brief description of the nature of this study, and asked for their consent to observe one of their tutorials and, if both the tutors and their students were willing, to conduct interviews of the students involved at the end. It was also made clear that all findings of this research would be anonymized and ethical guidelines followed always.

It was anticipated that, due to the 'cold' nature of the above approach, it was unlikely that most of the twenty-six tutors contacted would be either able or willing to participate in this pilot study. Whilst this method of opportunistic sampling had the advantage of convenience and manageability, it was recognised that it also had the disadvantages of not knowing whether the findings were representative and potentially producing a biased sample. To ensure that the study was manageable for the scope and length of this paper, while at the same time keeping the sample size as large as possible to minimise the potential for bias, the goal was to observe and/or interview no more than ten students altogether. Hence it was hoped that three to four tutors would consent to be involved, so that around six to twelve students could be observed and/or interviewed (on the basis that tutorials typically involve two to three students). Ultimately this target was achieved, as three tutors from three different Oxford colleges agreed to participate, with groups consisting of two to three students. In all, this pilot study involved seven law students in total (out of a cohort of around one hundred and eighty-five). ${ }^{68}$

Before commencing this pilot study, steps were taken to ensure that the study, which involved live participants, followed appropriate ethical guidelines. Informed consent was obtained from all participants, interviews were confidential and data generated were anonymized. Full ethics clearance was obtained from a university research ethics committee before commencing any data collection and during the process all participants were informed that their contribution to questionnaires and involvement in interviews was completely voluntary. On this basis, it is considered that the ethical procedures adhered to for the purposes of this

\footnotetext{
68 University of Oxford Undergraduate Admissions Statistics, https://www.ox.ac.uk/about/facts-andfigures/admissions-statistics/undergraduate?wssl=1 [Retrieved 17 April 2017].
} 
study were in accordance with the ethical guidelines for educational research set out by BERA, ${ }^{69}$ which underline the need for voluntary informed consent, privacy, openness and disclosure.

For the purposes of the discussion below, the tutors were defined as follows. Tutor 'A' gave a tutorial to three students - 'A1', 'A2' and 'A3' - all of whom were first years studying Tort Law, the topic of their tutorial being Psychiatric Injury. Tutor ' $B$ ' gave a tutorial to two students - 'B1' and 'B2' - who were second years studying Administrative Law, the topic of their tutorial being Jurisdiction. Tutor ' $C$ ' gave a tutorial to two students - 'C1' and 'C2' - who were first years studying Tort Law, the topic of their tutorial being Defences in Tort. Before the observations and interviews took place, information sheets and consent forms were provided to the tutors and students involved. To encourage student participation in interviews, the information sheets stated that taking part in this study might help students to get more out of their tutorials in future by reviewing their experiences, as well as potentially providing experience of research and questioning techniques that might be useful for them in further study or legal practice.

The findings of the observations and interviews are discussed below. Apart from the topics and students, there were many differences between the observations and interviews, which will be expanded upon in the next section. Tutors $A$ and $B$ conducted their tutorials in a traditional classroom setting (i.e. a tutor's college room), while $\mathrm{C}$ conducted his tutorial walking through the Oxford University Parks with his students beside him. The tutorials observed lasted between fifty minutes and one hour and five minutes and the student interviews afterwards lasted between seventeen and twenty-two minutes. All the students involved agreed to be interviewed except for A3.

\section{Discussion}

Having completed the primary data gathering stage of this pilot study, on analysing this data and comparing it, it was possible to identify several points of interest, similarities and differences in the data. To determine the effectiveness of the Oxford tutorial system in the teaching of an undergraduate QLD the key themes of the findings in this study are discussed below both in broad terms, by reference to strengths and weaknesses of tutorials, and specifically by reference to the main research question i.e. does the Oxford tutorial system help to stimulate critical thinking and foster a critical dialogue around feedback among law students?

\subsection{Strengths of tutorials}

In the interviews students appeared to agree with the view of Palfreyman that tutorials are more academically challenging and rigorous that lectures. As argued by Palfreyman, students genuinely felt encouraged to learn their subject of study thoroughly to avoid having their lack of understanding exposed in the setting of a tutorial, where they would be required engage in academic discussion with their tutors and peers. It was notable from the student interviews that the students all said that they did the same amount of preparation for their tutorials - exactly 15 hours in each case, which suggests that this figure is a guideline they have been given and may therefore reflect the actual amount of time they set aside for tutorial preparation. From the tutorial observations, it was clear that there was a very good rapport between the students and their tutors, although student comments in the interviews suggest that this may not be a universal feature of tutorials and very much depend on the tutor. It was also clear from the interviews and observations that both the nature

\footnotetext{
${ }^{69}$ British Educational Research Association (BERA) Ethical Guidelines for Educational Research
} (2011). 
and quantity of feedback given in tutorials varied greatly, and that although students were generally satisfied with this there was scope for improvement, particularly in terms of feedback for assessment preparation. Whilst students mostly commented in the interviews that tutorials were useful for learning some legal skills, there seemed to be a consensus that this was limited to argument and advocacy, which might suit those intending to be barristers but would be less useful for other careers in law. In the interviews students generally commented that they enjoyed tutorials, especially in comparison to lectures and seminars. Critical thinking seemed to contribute to this enjoyment i.e. the chance to form their own opinion on a subject, rather than simply learning it to pass an assessment. In contrast, students felt that the main weakness of tutorials was the lack of consistency, which was due largely to differences in the approaches of their tutors and to differences in the contributions of their tutorial partners.

\subsection{Weaknesses of tutorials}

Many of the issues identified in the interviews and observations reflect those referred to in the relevant literature and in previous studies. The weaknesses in the Oxford tutorial system identified in the literature review and the concerns raised by students in OUSU's study as summarised above were to some extent also reflected in the observations and interviews. The different levels of active participation by the students observed in the tutorials - A3 compared with A1 and A2 and C2 compared with $\mathrm{C} 1$ - reflect concerns raised by Mirfield about students who remain silent or who are otherwise unsuited to tutorials and Brookfield that participation in group discussion can be a mixed blessing. This also ties in with the concerns expressed by students in OUSU's study about tutorial partners who were either excessively quiet or excessively talkative to the point that other voices were drowned out. ${ }^{70}$ Another problem with the tutorial system identified by Mirfield - the risk that students end up relying only upon the essays produced by tutorials in their revision for exams appears well-founded given that two of the students interviewed (A1 and B2) expressly stated that they saw this as the main purpose of essays prepared for tutorials. In OUSU's study students also stated that one way of improving feedback in tutorials would be more pointers on how tutorial work could be turned into an essay in an exam. ${ }^{71}$ The risk of tutorials being used in this way is that "a method of teaching designed to open up argument sometimes ends up with a text that closes off argument." 72

\subsection{Assessment and feedback}

The tutorial observations and student interviews revealed, as identified by Ashwin, differing conceptions of the role of tutorials in terms of assessment and feedback both from the point of view of students and tutors. Some students saw tutorials as essential to assessment preparation, and needing to be more focused on assessment; others saw tutorials as being more about developing an understanding of the topic under discussion, with assessment preparation being something that students did in their own time, using the other resources available such as past papers and examiners' reports for this purpose. These views contrast with those of the OUEC that central to the tutorial system is the provision of regular and substantial feedback and formative assessment. The students interviewed did not necessarily share the concerns of students in OUSU's study relating to quality of feedback, at least in relation to the tutorials observed, although it seemed to be the case that

\footnotetext{
70 OUSU, supra n.3.

${ }^{71}$ OUSU, supra n.3.

72 Mirfield, supra n.35, p.46.
} 
some of their tutorials were more lacking in this respect than others. In relation to legal skills, again, the students interviewed did not share the exact concerns of students identified in OUSU's study; while they did have concerns, they seemed to relate more to the generality and applicability of the skills they were learning rather than any lack in this regard.

The findings of this pilot study also seem to bear out the potential of the Oxford tutorial system to benefit students by developing the ability to regulate their own learning, particularly through formative assessment and feedback. This was particularly evident in A's tutorial, where exercises that involved gaining an understanding of marking criteria and how to answer essay questions enabled the students to manage the improvement of their own learning in the future by setting learning goals and strategies for achieving them, all aspects of self-regulated learning. ${ }^{73}$ These tasks appear to explicitly develop self-regulated learning by going beyond simply providing feedback to empower the students to regulate aspects of their thinking, motivation and behaviour during learning. ${ }^{74} \mathrm{~A}$ 's tutorial also, however, highlights the potential limitation of the system that some students may not engage fully in tutorials. This raises the issue that the Oxford tutorial system may be more suitable for the most able students (i.e. those who are already self-regulated learners) and that others may be better served in less intensive learning environments. Equally, it may simply be that the tutor's role in such instances is to encourage more reticent students and help those less prepared for tutorials. If this is the case, then the Oxford tutorial has the potential not only to be of benefit to those students who are already self-regulated learners but also to help develop this attribute in less confident students.

\subsection{Critical thinking and critical dialogue}

From the observations and the interviews, it was clear that developing critical thinking skills through tutorial teaching and dialogic feedback was central to the system, as set out by the OLI. In each session, the students were expected to orally communicate, defend, analyse and critique the ideas of others as well as their own in conversations with their tutors and peers, not simply to recall what they learned (although they were expected to do this also). This approach aligns with the most commonly accepted aspects of critical thinking as summarised by Golding. As stated above, the chance to develop critical thinking skills also seems to be something very much appreciated by the students interviewed, all of whom expressed the view that they enjoyed putting forward and defending their opinions in both essays and tutorials.

A point made in A1 and A2's interview about leading a tutorial being a skill in itself appears relevant in the context of critical thinking. In all the tutorial observations, it was evident that one of the most important techniques used by tutors to encourage critical thinking in their students involved, not just asking questions, but getting the student to elaborate on their answers, using prompts both to challenge students and help them reflect on what they were saying as they were saying it. As was most apparent from B's tutorial, this applied as much between students and their peers as between students and their tutor. What seems to be important, as noted by Probert, ${ }^{75}$ is for the students to find out what they really understand by trying to explain material to someone else, whether that is their tutor or another student. This seems to go to the heart of what tutorials at Oxford are all about - the stimulation of

\footnotetext{
73 Nicol, supra n.27.

${ }^{74}$ Sadler, supra n.25.

${ }^{75}$ P. Probert, 'Engineering the tutorial experience'. In Palfreyman, D., ed. The Oxford Tutorial: "Thanks, You Taught Me How to Think," 2nd ed. (Oxford: Blackwell's, 2008) pp.61-67.
} 
critical thinking by argumentative dialogue i.e. the Socratic Method, as established at the university by Jowett in the nineteenth century.

This also seems to accentuate the importance of oral argument and presentation in tutorials, which has been commented upon by many academics previously. Ryan has claimed that the tutor teaches largely through questioning ${ }^{76}$ and Beck has stated that this questioning serves both a formative assessment function and as an aid that points students in directions they have not considered previously. ${ }^{77}$ Oral argument and presentation also help the tutor to determine the level of a student's understanding. As Fox points out, doing it in person may reveal the level of confidence the student has in his argument and perhaps to what degree he understands his own, or perhaps appropriated, argument. 78 This process may also reveal to students what they themselves know and understand, and thus serves the fundamental purpose of tutorials, that of teaching largely through questioning. ${ }^{79}$

Critical thinking is also one of the main skills gaps in legal education and training that needs to be addressed, ${ }^{80}$ and the Oxford tutorial system seems to be a useful way of tackling this deficiency. This is a model that - through small group discussion of feedback, oral presentation and argument - offers students an opportunity to develop their critical thinking skills. The need to improve such skills is identified by the LETR as a key area of concern in UK Higher Education. ${ }^{81}$ These practices also appear to meet the specific needs of law students, offering them the chance to engage in the sort of discussion and critical argument that will prepare them for legal professional practice.

\section{Conclusion}

It was recognised at the outset that there were several potential limitations to this study - intended to be a pilot - in view of the relatively small number of observations and interviews that took place, as well as the wide variation the tutorials in terms of setting, structure, content and so on. Also, as noted in the methodology section of this paper, opportunistic sampling was used to recruit participants who were available at the time of the study. Whilst this sampling method has the advantage of convenience and manageability, it is recognised that it has the disadvantage of not knowing whether findings are representative and potentially producing a biased sample. However, while this pilot study was not intended to be statistically significant it was considered that it could provide a level of detail concerning how students experience tutorials that is sufficient to answer the research question i.e. does the Oxford tutorial system help to stimulate critical thinking and foster a critical dialogue around feedback among law students? The literature review highlighted the fact that there is insufficient data available currently on how students experience tutorials. The purpose of the observations was to reveal activities, types of interaction, and the tutor's role in stimulating critical thinking and a critical feedback dialogue and to look at the range of student responses that show learning gain, engagement or otherwise. The purpose of the interviews was to reveal student perceptions of the tutorials - did they enjoy them, were they engaged, was feedback useful, did they feel better prepared for assessment (and legal practice), has their ability to think critically improved, what worked and did not work for them, what would they change etc.

\footnotetext{
76 D. Ryan, 'Perfection in politics and philosophy'. In Palfreyman, D., ed. The Oxford Tutorial: "Thanks, You Taught Me How to Think," 2nd ed. (Oxford: Blackwell's, 2008) pp.72-77.

${ }_{77}$ Beck, supra n.14, p.3.

${ }^{78}$ Fox, supra n.13, p.56.

${ }^{79}$ Ryan, supra n.76, p.72.

${ }^{80}$ LETR, supra n.33.

81 ibid.
} 
Considering these purposes, several tentative conclusions can be drawn from the findings of this pilot study, although it is recognised that given the sample size, these reflect the views of only a few students in a narrow range of subjects. There was a great deal of consistency in the tutorial observations and student interviews, as discussed above. There was a generally good rapport between the tutors and the students in all the tutorials, the setting was comfortable and informal, tutorials generally lasted around an hour, and feedback (both general and specific to essays prepared by students) formed an important part of the tutorial. The tutor's role in all the tutorials was to question students, prompt them to expand upon their answers, encourage them to self-reflect and self-question and to engage them in a dialogue around feedback that was critical in nature. All the students interviewed enjoyed tutorials and saw them as useful. They prepared for tutorials intensively and seemed to have some appreciation of the fact that the object was not simply to learn and memorize the material they were studying, but also to criticise it and their understanding of it. The one significant weakness of the tutorial system that all the students expressed was its potential for inconsistency depending on the approach of individual tutors.

Despite the similarities noted in the tutorial observations and student interviews, as discussed above, there was also a significant degree of variation in their setting, structure and content, especially given the small sample size. B's tutorial was very tightly structured, C's far less so; students were required to produce essays in advance of B and C's tutorials but not A's; A's tutorial had three students, B and C's only two; B's tutorial involved second years, with greater experience of tutorials than the first years involved in $A$ and C's tutorials; and there was greater interaction between students in B and C's tutorial than in A's. In a sense these differences might be said to be more superficial than the similarities, given the consistent importance in all the tutorials afforded to encouraging critical thinking in the students and engaging in a critical dialogue around feedback. Student perceptions of tutorials also differed, however, particularly in relation to feedback, with some students mainly seeing its value in tutorials in relation to preparing for assessment while others regarded tutorial feedback as having wider importance for improving their ability to think, argue and form and defend opinions.

It would be useful to conduct a larger scale study to investigate the significance of these differences as well as to explore several other issues. All the students interviewed had largely positive views on tutorials, but also referred to more negative experiences with other tutors. A larger sample size might be useful to identify other weaknesses in the tutorial system involving different tutors and students. In this regard, involving students at different points in their studies would seem desirable to determine whether this affects their tutorial experience. Would students in their first term view tutorials differently from those at the end of their first year or at the end of their final year? Would students in subjects traditionally regarded as more difficult for law students, such as Equity or Land Law, have a different view from those studying Tort and Administrative Law? It would also be interesting to involve students from a wider range of backgrounds. There was a very good rapport between the students and tutors involved in this study, all almost exclusively from white, British, middle-class backgrounds. Would this also be the case if the students were from a more diverse range of backgrounds in terms of nationality, social class, gender, disability and so on, and would any of these factors influence their views or experience of the tutorial system? Would a comparative study introducing law students at Oxford to the tutorials in larger groups that might be typical at another university (and vice versa) be helpful for investigating the strengths and weaknesses inherent in both models?

The above seem to be important issues to follow up on to determine the suitability of the Oxford tutorial system as a pedagogic model for other Higher Education Institutions to follow (while taking account of economic factors that might 
limit its transferability). Returning to the main research question, based on the tutorial observations and student interviews conducted for the purposes of this pilot study, it appears that the Oxford tutorial system has the potential to stimulate critical thinking and foster a critical dialogue around feedback among law students. This potential certainly seems worthy of further investigation in the context of an undergraduate QLD. 